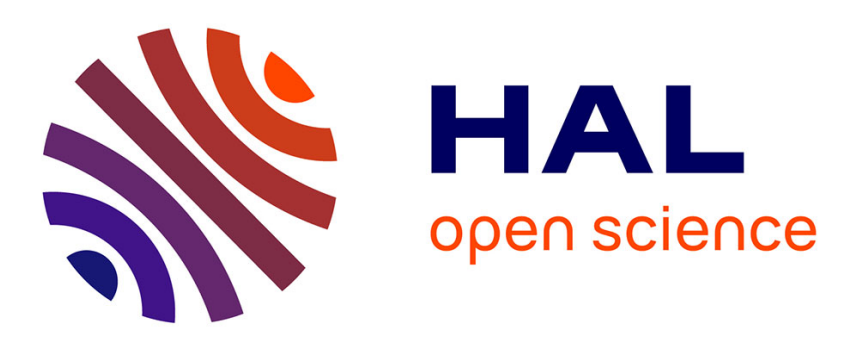

\title{
Impact of CYP2C19 phenotypes on escitalopram metabolism and an evaluation of pupillometry as a serotonergic biomarker
}

L. Noehr-Jensen, S. T. Zwisler, F. Larsen, S. H. Sindrup, P. Damkier, F. Nielsen, K. Brosen

\section{To cite this version:}

L. Noehr-Jensen, S. T. Zwisler, F. Larsen, S. H. Sindrup, P. Damkier, et al.. Impact of CYP2C19 phenotypes on escitalopram metabolism and an evaluation of pupillometry as a serotonergic biomarker. European Journal of Clinical Pharmacology, 2009, 65 (9), pp.887-894. 10.1007/s00228-009-0657-0 . hal-00534960

\author{
HAL Id: hal-00534960 \\ https://hal.science/hal-00534960
}

Submitted on 11 Nov 2010

HAL is a multi-disciplinary open access archive for the deposit and dissemination of scientific research documents, whether they are published or not. The documents may come from teaching and research institutions in France or abroad, or from public or private research centers.
L'archive ouverte pluridisciplinaire HAL, est destinée au dépôt et à la diffusion de documents scientifiques de niveau recherche, publiés ou non, émanant des établissements d'enseignement et de recherche français ou étrangers, des laboratoires publics ou privés. 


\title{
Impact of CYP2C19 phenotypes on escitalopram metabolism and an evaluation of pupillometry as a serotonergic biomarker
}

\author{
L. Noehr-Jensen • S. T. Zwisler • F. Larsen • \\ S. H. Sindrup • P. Damkier • F. Nielsen • K. Brosen
}

Received: 29 January 2009 /Accepted: 5 April 2009/Published online: 29 April 2009

(C) Springer-Verlag 2009

\begin{abstract}
Purpose To investigate the impact of cytochrome P450 2C19 (CYP2C19) phenotypes on escitalopram metabolism and to evaluate pupillometry as a serotonergic biomarker. Methods This was a double-blind, crossover design study with single and multiple doses of $10 \mathrm{mg}$ escitalopram and placebo in panels of CYP2C19 extensive (EM) and poor metabolisers (PM). Pupillometry was measured by a NeurOptics Pupillometer-PLR.

Results Five PM and eight EM completed the study. The CYP2C19 phenotype significantly affected the metabolism of escitalopram. The area under the time-plasma concentration curve $\left(\mathrm{AUC}_{0-24}\right)$ was 1.8 -fold higher in $\mathrm{PM}$ than in EM after both single and multiple doses. Escitalopram treatment did not affect the maximum pupil size, but it did
\end{abstract}

L. Noehr-Jensen $(\bowtie) \cdot$ S. T. Zwisler $\cdot$ P. Damkier $\cdot$ F. Nielsen $\cdot$

K. Brosen

Institute of Public Health, Clinical Pharmacology,

University of Southern Denmark,

J.B. Winslowvej 19, 2,

5000 Odense C, Denmark

e-mail: lnjensen@health.sdu.dk

S. T. Zwisler $\cdot$ S. H. Sindrup

Department of Clinical Neurology, Odense University Hospital,

Sdr. Boulevard 29,

5000 Odense C, Denmark

F. Larsen

Clinical Pharmacology \& Pharmacokinetics,

H. Lundbeck A/S, Ottiliavej 9,

2500 Copenhagen, Valby, Denmark

P. Damkier

Department of Biochemistry, Pharmacology and Genetics,

Odense University Hospital,

Sdr. Boulevard 29,

5000 Odense C, Denmark statistically significantly decrease the relative amplitude of the pupil light reflex compared to the placebo; this effect was equal in both phenotype groups.

Conclusions The CYP2C19 polymorphism affects escitalopram metabolism, but the difference does not justify dose adjustment. The puzzling results from pupillometry can be due to interplay between a central and a local serotonergic effect. Based on these results, pupillometry can not be recommended as a serotonergic biomarker.

Keywords Biomarker CYP2C19 - Escitalopram · Pharmacodynamics $\cdot$ Pharmacokinetics $\cdot$ Pupillometry

\section{Introduction}

Escitalopram is the S-enantiomer of the selective serotonin reuptake inhibitor (SSRI) citalopram, and it is used for the treatment of depression, a variety of other affective disorders, a number of anxiety disorders and obsessive compulsive disorder (OCD) [1]. Citalopram is a racemate consisting of equal proportions of an $\mathrm{R}$ - and an Senantiomer, and it has been demonstrated that the $\mathrm{S}$ enantiomer is a far more potent inhibitor of the presynaptic serotonin transporter (SERT) than the R-enantiomer and, consequently, that the therapeutic effect of citalopram probably originates almost exclusively from S-citalopram [2]. The R-enantiomer inhibits the effect of S-citalopram through allosteric modulation of the SERT [3]. The antidepressant mechanism of escitalopram has not yet been fully elucidated, but the prevailing hypothesis is that it is mediated by an inhibition of SERT, leading to an increased level of serotonin (5-HT) in the synaptic cleft [4].

Previous studies have shown that racemic citalopram is mainly metabolised by cytochrome P450 2C19 (CYP2C19) 
[5]. Up to $5 \%$ of Blacks and Caucasians are phenotyped as poor metabolisers (PM), whereas up to $20 \%$ of Asians are $\mathrm{PM}$ [6]. There are at least nine different variants of the CYP2C19 gene associated with no enzyme activity [7, 8] .

Racemic citalopram is enantioselectively metabolised via CYP2C19, and the S-enantiomer is more rapidly metabolised than the R-enantiomer, as was demonstrated in a panel study of healthy volunteers [9] and in a retrospective study of therapeutic drug monitoring samples from psychiatric patients [10]. To the best of our knowledge, no formal panel study addressing the role of CYP2C19 in the metabolism of escitalopram has been performed. Consequently, the main aim of this study was to investigate the impact of CYP2C19 polymorphism, as assessed by phenotype, on escitalopram and demethylescitalopram pharmacokinetics (PK) in panels of CYP2C19 extensive metabolisers (EM) and CYP2C19 PM.

The pupil diameter is known to be a useful biomarker in studies of opioid-like drugs and is capable of distinguishing between CYP2D6 EM and PM after a single dose of tramadol [11]. In a recent double-blind, crossover study of healthy subjects, citalopram and sertraline induced a marked acute and steady increase of pupil diameter, but the mechanism is unclear [12].

Based on the results of pupillometry as a biomarker of opioid effect and CYP2D6 activity, we decided to implement and evaluate pupillometry as a potential biomarker of the serotonergic effect of escitalopram, as a broad range of plasma concentrations of escitalopram was expected in the study population. Thus, the secondary purpose of this study was to evaluate static and dynamic pupillometry as a possible biomarker for the serotonergic effect of escitalopram. Our hypothesis was that the anticipated mydriatic effect of escitalopram - all other things equal-would be higher in CYP2C19 PM than in CYP2C19 EM due to the higher plasma concentrations this drug.

\section{Methods and materials}

Study design and study procedures

The study was conducted as a randomised, double-blind, placebo-controlled, two-phase, crossover, phenotype panel trial with single and multiple doses (1 dose/day for 8 days) of $10 \mathrm{mg}$ escitalopram (H. Lundbeck A/S, Copenhagen, Denmark) and equivalent placebo (H. Lundbeck A/S). Subjects were classified into groups according to their CYP2C19 phenotype, as determined by their omeprazole metabolic capacity. CYP2C19 genotypes were determined after the subjects were entered into the study.

The treatment consisted of two phases: one with escitalopram and one with placebo. A total of 20 packages of trial medication were packed by Hospital Pharmacy Fyn,
Odense University Hospital. Randomisation of treatment order was done in ten blocks of two subjects. The individual package of trial medication was randomly chosen by the subjects. On the first study day, subjects came to the Department of Clinical Pharmacology at 7:30 a.m. They were instructed beforehand to eat their usual breakfast at 7:00 a.m. and were not to eat or drink anything except water until they received a free meal at 12:00 noon. A venous canula was placed in the forearm of the subjects for blood sampling. At 8:00 a.m., the drug was taken with approximately $100 \mathrm{ml}$ of tap water. Blood samples and pupillometry were undertaken at pre-arranged times, as outlined below. Subjects stayed at the trial unit until 4:00 p.m., then the venous canula was removed, and they were free to leave the trial unit. Subjects returned shortly before 8:30 p.m. and 8:00 a.m. the next morning for pupillometry and blood sampling. Participants were instructed to continue their intake of the trial medication at 8:00 a.m. for the following five days. On day 8 , subjects returned to the trial unit and the same procedure as that carried out on the first day was repeated. Following the multiple dose regimen, blood sampling and pupillometry were performed on an outpatient basis, every morning for 6 days. The two phases were separated by at least 15 days of wash-out, and a follow-up visit was arranged at least 15 days after the last dose.

Information on adverse events was recorded by the simple question: "How are you?" when the subjects turned up for blood sampling and pupillometry. The subjects were also instructed to report any adverse event that occurred during the 5 days of self-administered medication.

This study was registered in the European Clinical Trial Database (EudraCT no.: 2006-001976-19). The protocol was approved by the Danish Medicines Agency (J. no: 26123153), the Danish Data Protection Agency (J. no. 2006-416658) and the Regional Committee on Biomedical Research Ethics of Vejle and Funen Counties (Project ID: VF20060045). The study was conducted in accordance with Good Clinical Practice (GCP) and monitored by the GCPunit, Odense University Hospital, Odense, Denmark. The trial was registered in the U.S. National Institute of Health register (www.clinicaltrials.gov) as trial NCT00397059.

\section{Subjects}

Subjects were selected from 306 healthy volunteers phenotyped for CYP2C19 using omeprazole as a probe drug [13] who had been recruited mainly among students at the University of Southern Denmark, Odense, Denmark and University College Lillebaelt, Denmark. All subjects (101 men and 205 women, aged 19-45 years) were Caucasian. More than $95 \%$ belonged to the Nordic population, whereas the remaining $5 \%$ or so came from southern Europe or the Middle East. 
Nine subjects were phenotyped as PM, and all were invited to participate in the study. Two declined-one due to family reasons and one due to a previous experience with adverse effects during treatment with escitalopram - and a third PM was excluded as she had started treatment with escitalopram after being phenotyped.

Six PM (one man and five women) and eight EM (one man and seven women) gave informed written consent. One female PM withdrew her consent before receiving any trial medication due to a change in residence. In total, 13 subjects completed the trial. All subjects had normal cardiovascular, renal and hepatic functions as assessed by a physical examination, review of the medical history and appropriate laboratory testing. Subjects were interviewed on their use of drugs, herbal medicine and alcohol; none of the subjects had any history of drug or alcohol abuse. The eight subjects in the EM group had a median age of 25 years (range 21-32 years), a median weight of $67 \mathrm{~kg}$ (range 51-88 kg), and a median height of $169.5 \mathrm{~cm}$ (range $165-173 \mathrm{~cm})$. The five PM had a median age of 24 years (range 21-27 years), a median weight of $59 \mathrm{~kg}(55-74 \mathrm{~kg}$ ) and a median height of $169 \mathrm{~cm}$ (range 165-177 cm). There were no differences in mean age or body mass index between the phenotype groups $(P=0.52$ and $P=0.25$, respectively). All subjects were genotyped as CYP2D6 EM.

Phenotyping The CYP2C19 phenotype was determined with omeprazole (AstraZeneca, Albertslund, Denmark) as probe drug $[14,15]$. The metabolic ratio (MR) of omeprazole to hydroxyomeprazole was used to assess the individual capacity of CYP2C19. The EM were defined as having a $\mathrm{MR}<6$ and the $\mathrm{PM}$ as having a MR $\geq 6[14,15]$.

In the total group, the $297 \mathrm{EM}$ had a median MR of 0.9 (range 0.07-5.1), and the nine PM had a median MR of 13.6 (range 6.3-25.6). In the study reported here, the eight EM had a median MR of 0.9 (range 0.3-1.7), and the five PM had median MR of 13.6 (range 6.4-16.3). There was no statistical significant difference in the median MR of the subjects participating in the clinical study and that of the entire population, either in the EM group or the PM group ( $P=0.59$ and $P=0.84$, respectively).

Genotyping After inclusion to the trial, each subject was genotyped for $C Y P 2 C 19 * 2$, *3, and*4. The CYP2C19*2 allele was identified using a commercially available 5 exonuclease-dependent assay that includes proprietary amplification primers and two allele-specific fluorescencelabeled probes (Applied Biosystems, Foster City, CA). Determination of $C Y P 2 C 19^{*} 3$ and $C Y P 2 C 19^{*} 4$ were based on PCR analysis) and restriction enzyme treatment of amplified fragments $[16,17]$.

The $C Y P 2 C 19$ genotype distribution in accordance with the phenotypes were: EM: CYP $2 C 19^{*} 1 / * 1 \quad(n=7)$,
CYP2C19*1/*2 (n=1); PM: CYP2C19*1/*2 $(n=1)$, CYP $2 C 19 * 2 * 2(n=3)$ and $C Y P 2 C 19 * 2 * 4(n=1)$.

Blood samples Blood samples for the PK analysis were drawn prior to and at $1,2,3,4,6,8,12$ and $24 \mathrm{~h}$ after the administration of the single and multiple dose medication. Following the multiple dose treatment, blood sampling was repeated every $24 \mathrm{~h}$ (at 8:00 a.m.) until $144 \mathrm{~h}$ after last medication. Samples $(2 \times 10 \mathrm{ml})$ of K-EDTA blood were drawn at each sampling time; these were centrifuged for 10 $\min$ at $2400 \mathrm{~g}$ and the plasma separated and kept at $-20^{\circ} \mathrm{C}$ until drug analysis.

\section{Drug analysis}

Escitalopram and demethylescitalopram were extracted from plasma using Bond Elut-C18 solid-phase extraction (SPE; $100 \mathrm{mg}, 3 \mathrm{~mL}$ ) cartridges (Varian, Palo Alto, CA). The SPE cartridge was preconditioned by $2 \mathrm{~mL}$ methanol, $1 \mathrm{~mL} 1 \mathrm{~mol} / \mathrm{L}$ hydrochloric acid and $1 \mathrm{~mL}$ Milli-Q water. A $1 \mathrm{~mL}$ aliquot of plasma and $10 \mu \mathrm{L} 0.1 \mathrm{mmol} / \mathrm{L}$ alprenolol (internal standard) was whirlimixed for $5 \mathrm{~s}$ and applied to the SPE cartridge. The sample was allowed to run slowly through the column by the use of gravity and a minimum use of vacuum. This was followed by a washing procedure

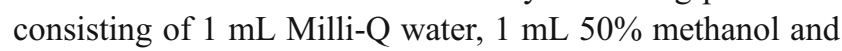
$1 \mathrm{~mL}$ acetonitril. The columns were allowed to dry $1 \mathrm{~min}$ at full vacuum. The compounds were eluted using $1 \mathrm{~mL}$ of a freshly prepared $2 \%$ formic acid in methanol. The eluent was evaporated to dryness at $50^{\circ} \mathrm{C}$ under a gentle stream of nitrogen. The compounds were redissolved in $200 \mu \mathrm{L}$ of eluent A (see below) and transferred to $300-\mu \mathrm{L}$ conical high-performance liquid chromatography (HPLC) microvials. The vials were centrifuged at $5000 \mathrm{~g}$ for $2 \mathrm{~min}$, and a $125-\mu \mathrm{L}$ sample was transferred to a new microvial. A 75 $\mu \mathrm{L}$ aliquot was injected onto the analytical system that consisted of a LaChrom HPLC system equipped with a fluorescence detector $\left(\lambda_{\mathrm{ex}}=250 \mathrm{~nm} ; \lambda_{\mathrm{em}}=325 \mathrm{~nm}\right)$ (MerckHitachi, Darmstadt, Germany). The separation was performed on a $150 \times 4.6 \mathrm{~mm}$ Synergi Polar-RP column (particle size $4 \mu \mathrm{m}$ ) (Phenomenex, Torrance, CA) using a two-phase gradient elution. The eluents consisted of $10 \mathrm{mmol} / \mathrm{L} \mathrm{KH}_{2} \mathrm{PO}_{4}(\mathrm{pH} 4)$ :acetonitril (67:33) (eluent $\mathrm{A}$ ) and $10 \mathrm{mmol} / \mathrm{L} \mathrm{KH}_{2} \mathrm{PO}_{4}(\mathrm{pH}$ 4):acetonitrile (40:60) (eluent B). The gradient profile was $0-12 \mathrm{~min}: 0 \% \mathrm{~B} ; 12.1-14 \mathrm{~min}$ : 0-100\% B, $14.1-20 \mathrm{~min}: 100 \% \mathrm{~B}$; $20.1-22 \mathrm{~min}: 100-0 \%$ B; 22.1-35 min: $0 \% \mathrm{~B}$. The flow rate was $1 \mathrm{~mL} / \mathrm{min}$.

The linearity of the method was investigated for escitalopram and demethylescitalopram in a range of 0 $200 \mathrm{nmol} / \mathrm{L}$. The correlation coefficient for each compound was $>0.996$. The mean recovery of the extraction procedure was $86 \%$ for escitalopram and $88 \%$ for demethylescitalo- 
pram. The intraday variability was $<6 \%$ for escitalopram and $<5 \%$ for demethylescitalopram. The interday variability ( $n=5$ days) was investigated for three concentration levels $(7.5,20$ and $38 \mathrm{nmol} / \mathrm{L})$ and was $<1 \%$ for escitalopram and $<1.3 \%$ for demethylescitalopram. The accuracy for escitalopram ranged from 100.5 to $101.2 \%$ and from 99.6 to $100.9 \%$ for demethylescitalopram. The lower limit of detection (LOD) was $3 \mathrm{nmol} / \mathrm{L}$ and the lower limit of quantification (LOQ) was $4 \mathrm{nmol} / \mathrm{L}$ for both escitalopram and demethylescitalopram. The following conversion factors were used: $1 \mathrm{ng} / \mathrm{ml}$ escitalopram=3.08 $\mathrm{nmol} / \mathrm{L}$; $1 \mathrm{ng} / \mathrm{ml}$ demethylescitalopram $=3.22 \mathrm{nmol} / \mathrm{L}$.

Pupillometry Static and dynamic pupillometry was performed using the hand-held infra-red NeurOptics Pupillometer-PLR (NeurOptics, San Clemente, CA). The following parameters were measured: maximum pupil diameter (mm) (MAX) and minimum pupil diameter (mm) (MIN). Relative amplitude (REL AMPL) was calculated as (MAX - MIN)/MAX. A schematic drawing of the pupil trajectory profile displayed as a function of time and pupil size is depicted in Fig. 1.

Pupillometry was recorded prior to medication and at 1 , $1.5,2,2.5,3,4,5,6,7,8,12$, and $24 \mathrm{~h}$ after medication intake on days 1 and 8 . After multiple doses, the measurements were repeated at 24-h intervals until $144 \mathrm{~h}$ after the last dose had been taken.

Pupillometry was carried out in a room without windows, and the light intensity was kept at $5 \mathrm{~cd} \mathrm{~m}^{-2}$ (Testo 545 Light Level Lux Meter; Testo, Hampshire, UK). After a 2-min period of dark adaptation, the subject was instructed to focus on a mark placed approximately $4 \mathrm{~m}$ away in order to avoid accommodation during the measurement. Based on the results from the pupillometer evaluation, we decided to record two measurements with an interval of $2 \mathrm{~min}$. The maximum limit of acceptable difference between the two measurements of maximum pupil diameters was set at $0.7 \mathrm{~mm}$; if the limit was exceeded, a third measurement was performed. The mean values of the two measurements were used in subsequent analyses.

Pharmacokinetic data analysis The PK parameters for escitalopram and demethylescitalopram were calculated by standard non-compartmental methods using the software package WinNonlin Professional, version 5.1 (Pharsight, Mountain View, CA). The area under the plasma concentration-time curve extrapolated to infinity $\left(\mathrm{AUC}_{0-\infty}\right)$ of escitalopram and demethylescitalopram was calculated using the linear trapezoidal method. The maximum plasma concentration $\left(\mathrm{C}_{\max }\right)$ and time to maximum plasma concentration $\left(t_{\max }\right)$ of escitalopram and demethylescitalopram were read directly from the data. The terminal elimination half-life $\left(t_{1} / 2\right)$ of escitalopram and demethylescitalopram was calculated as: $t_{1 / 2}=\ln 2 / \lambda$, where $\lambda$ is the terminal slope of the log plasma concentration versus the time plot, calculated by linear regression.

Pharmacodynamic data analysis The area under effect curve (AUEC) was calculated for the MAX and REL AMPL parameters by linear interpolation using the noncompartmental model 220 for drug effect in the software package WinNonlin. In an attempt to minimise errors in the analysis of pupil data, AUEC was calculated solely for the period before drug intake $(0 \mathrm{~h})$ until $8 \mathrm{~h}$ after drug intake.

\section{Statistical methods}

Sample-size calculation Sample size calculation was based on the primary outcome: differences in AUC for escitalopram between CYP2C19 EM and PM. Based on an interindividual coefficient of variance for AUC of $40 \%$, it was estimated that a true difference of $67 \%$ could be detected, given a two-sided level of significance $(\alpha)$ of 0.05 and a power $(\beta)$ of $80 \%$, by using eight individuals in each group.
Fig. 1 Schematic drawing of pupil diameter versus time. A single light stimulus is given at time $=0 \mathrm{~s}$

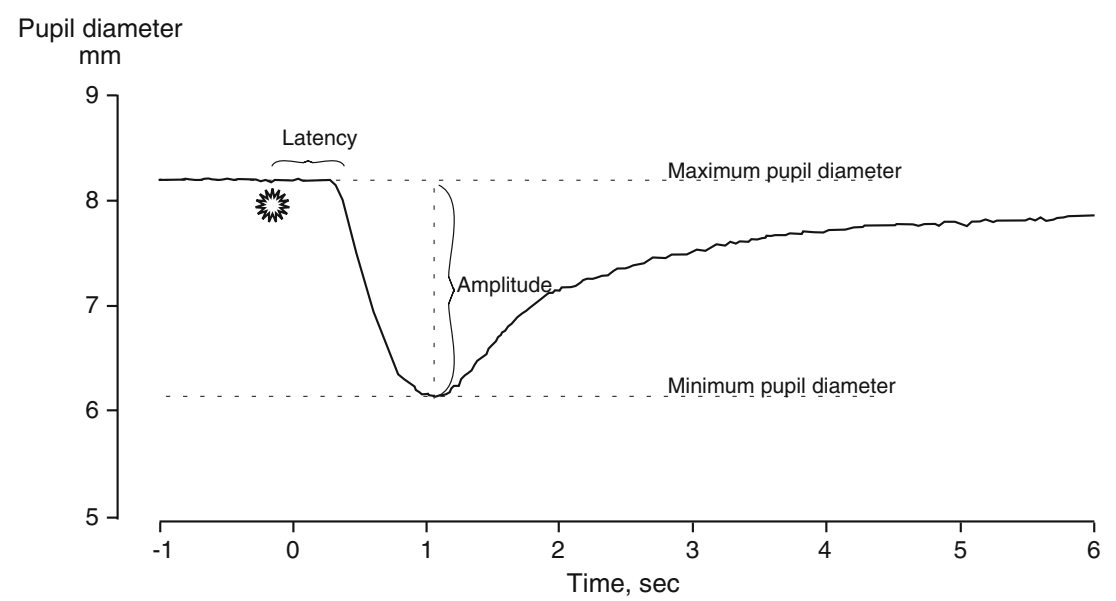


Pharmacokinetics and pharmacodynamics Data are presented as medians and ranges, unless otherwise indicated. Before statistical analysis, all data except $t_{\max }$ were transformed to the natural logarithm to create a Gaussian distribution. Parameters were transformed back to the original scale when the effects were described.

Statistical inferences of phenotype were analysed by an unpaired $t$ test and are presented as geometric mean ratios with $95 \%$ confidence intervals $(\mathrm{CI})$ and associated $P$ values. Inference tests on $t_{\max }$ were analysed by Hodges-Lehmann estimates of median differences with 95\% CI. Statistical inferences of treatment on pupil parameters were analysed by a paired $t$ test and are presented as geometric mean ratios with 95\% CI and associated $P$ values. Statistical analyses were performed using GraphPad QuickCalcs (http://graphpad.com/ quickcalcs/index.cfm) (GraphPad Software, San Diego, CA), StatXact-3 (Cytel Software, Cambridge, MA) and Microsoft Office Excel 2007 (Microsoft Denmark ApS, Hellerup, Denmark).

\section{Results}

Pharmacokinetics The pharmacokinetic parameters of escitalopram and demethylescitalopram and statistical inference are listed in Table 1. The median plasma concentration versus time profile after a single dose of $10 \mathrm{mg}$ escitalopram is presented in Fig. 2. The median escitalopram plasma concentration versus time profile after the last of multiple doses of $10 \mathrm{mg}$ escitalopram is presented in Fig. 3.

The single dose $\mathrm{AUC}_{0-\infty}$ and the multiple dose $\mathrm{AUC}_{0-24}$ were statistically significantly at 1.8 -fold higher in the $\mathrm{PM}$ than in the EM. The oral clearance $(\mathrm{CL} / \mathrm{F})$ was about 0.5 fold lower and the $t_{1 / 2}$ was 1.5 -fold higher in the PM. The phenotype did not affect the maximum plasma concentrations after a single dose, but after eight daily doses, the median $\mathrm{C}_{\max }$ was 1.6 fold $(95 \%$ CI $1.11-2.25 ; P=0.015)$ higher in the PM.

In both phenotype groups, the $\mathrm{AUC}_{0-24}$ for multiple doses tended to be higher than the single-dose $\mathrm{AUC}_{0-\infty}$. The

Table 1 Median and range pharmacokinetic values for escitalopram and demethylescitalopram after the oral administration of 10 mg escitalopram as a single and multiple dose, with statistical inference of the ratio between poor (PM) and extensive metabolisers (EM) of cytochrome P450 2C19

\begin{tabular}{|c|c|c|c|c|}
\hline Component/treatment & $\mathrm{PM}(n=5)$ & $\operatorname{EM}(n=8)$ & Statistical inference & $P$ value \\
\hline \multicolumn{5}{|c|}{ Escitalopram/single dose of escitalopram } \\
\hline $\mathrm{C}_{\max }, \mathrm{nmol} / \mathrm{L}$ & $46.0(33.6-71.5)$ & $38.7(29.7-75.24)$ & $1.16(0.79-1.70)^{\mathrm{b}}$ & 0.41 \\
\hline $\mathrm{t}_{\max }, \mathrm{h}$ & $4.0(2.0-4.1)$ & $3.5(2.0-8.0)$ & $0.01(-3.00-1.05)^{\mathrm{c}}$ & 0.98 \\
\hline $\mathrm{AUC}_{0 \rightarrow \infty}, \mathrm{nmol} \mathrm{h} / \mathrm{L}^{\mathrm{a}}$ & $2195(1618-3295)$ & $1082(885-2182)$ & $1.82(1.26-2.64)^{\mathrm{b}}$ & 0.0046 \\
\hline $\mathrm{AUC}_{0 \rightarrow 24}, \mathrm{nmol} \mathrm{h} / \mathrm{L}$ & $811(613-1023)$ & $593(488-968)$ & $1.26(0.95-1.69)^{\mathrm{b}}$ & 0.10 \\
\hline$t_{1 / 2}, h^{a}$ & $38(26-52)$ & $21(17-31)$ & $1.67(1.25-2.23)^{\mathrm{b}}$ & 0.0026 \\
\hline $\mathrm{CL} / \mathrm{F}, \mathrm{L} / \mathrm{h}^{\mathrm{a}}$ & $14.0(9.4-19.0)$ & $28.6(14.1-34.8)$ & $0.54(0.38-0.80)^{\mathrm{b}}$ & 0.0046 \\
\hline $\mathrm{V}_{\mathrm{z}} / \mathrm{F}, \mathrm{L}^{\mathrm{a}}$ & $702(530-968)$ & $789(579-1029)$ & $0.91(0.70-1.19)^{\mathrm{b}}$ & 0.48 \\
\hline \multicolumn{5}{|c|}{ Escitalopram/multiple doses of escitalopram } \\
\hline $\mathrm{C}_{\max }, \mathrm{nmol} / \mathrm{L}$ & $153(95-194)$ & $91(61-136)$ & $1.58(1.11-2.25)^{\mathrm{b}}$ & 0.015 \\
\hline $\mathrm{t}_{\max }, \mathrm{h}$ & $3.1(2.0-6.0)$ & $2.6(2.0-6.0)$ & $0.05(-1.03-1.97)^{\mathrm{c}}$ & 0.85 \\
\hline $\mathrm{AUC}_{0 \rightarrow 24}, \mathrm{nmol} \mathrm{h} / \mathrm{L}$ & $2785(1972-3800)$ & $1501(1094-2383)$ & $1.80(1.30-2.47)^{\mathrm{b}}$ & 0.0020 \\
\hline$t_{1 / 2}, h$ & $35(34-61)$ & $28(23-31)$ & $1.49(1.18-1.88)^{\mathrm{b}}$ & 0.0029 \\
\hline $\mathrm{CL} / \mathrm{F}, \mathrm{L} / \mathrm{h}$ & $11.1(8.1-15.6)$ & $20.6(12.9-28.2)$ & $0.56(0.40-0.77)^{\mathrm{b}}$ & 0.0020 \\
\hline $\mathrm{V}_{\mathrm{z}} / \mathrm{F}, \mathrm{L}$ & $704(532-898)$ & $893(578-1145)$ & $0.83(0.63-1.09)^{\mathrm{b}}$ & 0.16 \\
\hline \multicolumn{5}{|c|}{ Demethylescitalopram/multiple doses of escitalopram } \\
\hline $\mathrm{C}_{\max }, \mathrm{nmol} / \mathrm{L}$ & $23.7(13.7-25.8)$ & $23.9(21.6-33.9)$ & $0.80(0.61-1.04)$ & 0.095 \\
\hline $\mathrm{t}_{\max }, \mathrm{h}$ & $4.8(0.9-6.1)$ & $5.1(2.2-12.2)$ & $-1.12(-6.23-1.98)$ & 0.52 \\
\hline $\mathrm{AUC}_{0 \rightarrow 24}, \mathrm{nmol} \mathrm{h} / \mathrm{L}$ & $486(284-505)$ & $485(437-726)$ & $0.79(0.61-1.02)$ & 0.066 \\
\hline$t_{1 / 2}, h$ & $65(45-72)$ & $38(29-50)$ & $1.62(1.28-2.04)$ & 0.0008 \\
\hline
\end{tabular}

$\mathrm{C}_{\max }$, Maximum observed plasma concentration; $\mathrm{t}_{\max }$, time to $\mathrm{C}_{\max } ; \mathrm{AUC}_{0-\infty}$, area under concentration-time curve from time zero to infinity; $\mathrm{AUC}_{0-24}$, area under concentration-time curve from time zero to $24 \mathrm{~h} ; \mathrm{t}_{1 / 2}$, apparent elimination half-life in plasma; $\mathrm{CL} / \mathrm{F}$, oral clearance; $\mathrm{V}_{\mathrm{z}} / \mathrm{F}$, volume of distribution

${ }^{\text {a }}$ Sampling period only $24 \mathrm{~h}$

${ }^{\mathrm{b}}$ Geometric mean ratio (PM/EM) $(95 \%$ confidence interval) and $P$ value

c Hodges-Lehmans estimates of median difference (95\% confidence interval) and $P$ value 
Fig. 2 Median plasma concentrations of escitalopram versus the time profile after a single dose of $10 \mathrm{mg}$ escitalopram. Broken line Cytochrome P450 2C19 (CYP2C19) extensive metaboliser (EM), solid line CYP2C19 poor metaboliser (PM)

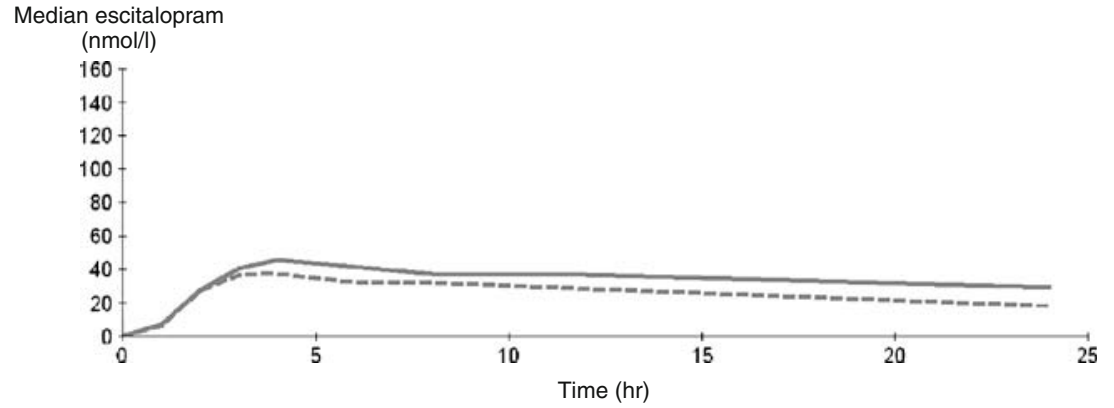

difference was statistically significant in the EM group $(P=$ $0.007)$, but not in the PM group ( $P=0.181)$.

The PK parameters of demethylescitalopram after a single dose of $10 \mathrm{mg}$ escitalopram were not calculated as more than half of the plasma samples had concentrations below the LOQ, and the $t_{1 / 2}$ could only be estimated in three of the 13 subjects.

There were no statistically significant differences in $\mathrm{C}_{\max }, \mathrm{t}_{\max }$ or $\mathrm{AUC}_{0-24}$ between the PM and EM after multiple dosing of escitalopram. The $t_{1 / 2}$ was statistically significantly longer in the PM than in the EM (65 vs. 38 h, respectively).

After multiple doses of escitalopram, the demethylescitalopram was $34 \%$ (range 26-60\%) that of escitalopram, measured as the $\mathrm{AUC}_{0-24}$ in the $\mathrm{EM}$ group, compared to $17 \%$ (range 9-23\%) in the PM group. The differences between phenotype groups were statistically significantly different, with a geometric mean ratio of $0.44(95 \%$ CI $0.30-0.64 ; P=0.0006)$.

Pharmacodynamics Pupillometry data is presented as the AUEC median and range values together with statistical inferences of the difference between treatment with placebo and escitalopram in Table 2.

The $A_{U E C} C_{\text {REL AMPL }}$ was significantly decreased during treatment with both single and multiple doses of escitalopram compared to the placebo. This effect persisted when subjects were divided in phenotype groups, but the effect was not statistically significant in PM in the multiple-dose regimen. The effect was equal in both phenotype groups, as seen by the overlapping 95\% CI in Table 2.
The $\mathrm{AUEC}_{\text {max }}$ was not affected by escitalopram treatment compared to placebo.

Safety and tolerability A total of eight subjects reported adverse events during one of the treatment phases: six reported more than one adverse event, and two did so during the placebo phase. None of the adverse effects were serious, and all disappeared shortly after discontinuation of treatment. The results of all clinical laboratory tests carried out at the follow-up visits were considered to be within the normal range.

\section{Discussion}

Our results are the first to demonstrate in a formal panel study of healthy phenotyped subjects that the CYP2C19 phenotype significantly affects the PK of escitalopram. Drug exposure measured as the AUC was 1.8-fold higher in PM than in EM both after a single dose and at steady state. The higher drug exposure is probably due to an impaired metabolism, as seen by the significant difference in total body clearance, and not due to differences in drug absorption, as indicated by the lack of difference in $\mathrm{C}_{\max }$ following a single dose of escitalopram.

We were unable to identify any comparable EM/PM panel studies of escitalopram in the literature, but the topic has indirectly been addressed in a Swedish panel study of EM and PM treated with racemic citalopram $2 \times 10 \mathrm{mg}$ /day for 7 days [9]. These researchers estimated a mean $\mathrm{AUC}_{0-12}=$ $530 \mathrm{nmol} / \mathrm{L} \mathrm{h}$ in the $\mathrm{EM}$ group versus a mean $\mathrm{AUC}_{0-12}=$
Fig. 3 Median plasma concentrations of escitalopram versus time profile after multiple doses of $10 \mathrm{mg}$ escitalopram. Broken line CYP2C19 EM, solid line CYP2C19 PM

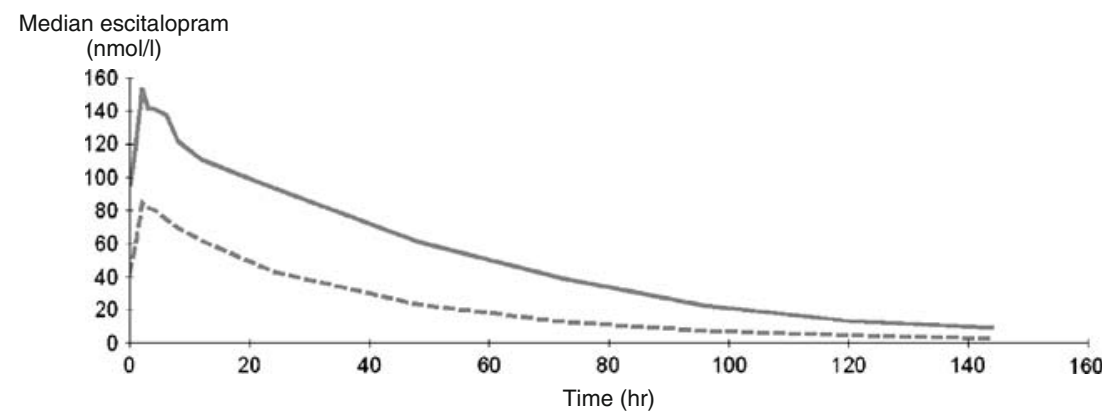


Table 2 Median and range of the area under the effect curve (AUEC) for the pupillometry data, following the administration of single or multiple oral doses of $10 \mathrm{mg}$ escitalopram or placebo, with statistical inference of the ratio between treatments

AUEC $_{\text {MAX }}$, Area under effecttime curve for maximum pupil diameter; $\mathrm{AUEC}_{\mathrm{REL}} \mathrm{AMPL}$, area under effect-time curve for relative light reflex amplitude

${ }^{a}$ Geometric mean ratio of AUEC (escitalopram treatment)/ AUEC (placebo treatment), with the $95 \%$ confidence interval given in parenthesis

\begin{tabular}{|c|c|c|c|c|}
\hline Treatment & Escitalopram & Placebo & Statistical inference $^{a}$ & $P$ value \\
\hline \multicolumn{5}{|c|}{ Single dose, all $(n=13)$} \\
\hline $\mathrm{AUEC}_{\mathrm{MAX}}$ & $3521(3098-3897)$ & $3463(2907-4027)$ & $1.01(0.98-1.05)$ & 0.51 \\
\hline $\mathrm{AUEC}_{\text {REL AMPL }}$ & $163(114-204)$ & $192(148-223)$ & $0.88(0.84-0.93)$ & 0.0004 \\
\hline \multicolumn{5}{|c|}{ Multiple doses, all $(n=13)$} \\
\hline $\mathrm{AUEC}_{\mathrm{MAX}}$ & $3464(2837-3794)$ & $3497(2940-3985)$ & $0.97(0.94-1.01)$ & 0.14 \\
\hline $\mathrm{AUEC}_{\text {REL AMPL }}$ & $170(112-210)$ & $191(152-226)$ & $0.91(0.86-0.96)$ & 0.0019 \\
\hline \multicolumn{5}{|c|}{ Single dose, poor metabolisers $(n=5)$} \\
\hline $\mathrm{AUEC}_{\mathrm{MAX}}$ & $3531(3098-3897)$ & $3522(3420-4027)$ & $1.00(0.95-1.06)$ & 0.88 \\
\hline $\mathrm{AUEC}_{\text {REL AMPL }}$ & $160(156-180)$ & $183(169-198)$ & $0.89(0.81-0.97)$ & 0.023 \\
\hline \multicolumn{5}{|c|}{ Multiple doses, poor metabolisers $(n=5)$} \\
\hline AUEC $_{\text {MAX }}$ & $3533(2837-3794)$ & $3592(3387-3985)$ & $1.00(0.97-1.05)$ & 0.62 \\
\hline $\mathrm{AUEC}_{\mathrm{REL}} \mathrm{AMPL}$ & $163(153-198)$ & $189(170-194)$ & $0.94(0.86-1.03)$ & 0.12 \\
\hline \multicolumn{5}{|c|}{ Single dose, extensive metabolisers $(n=8)$} \\
\hline AUEC $_{\text {MAX }}$ & $3479(3256-3767)$ & $3451(2907-3581)$ & $1.02(1.96-1.08)$ & 0.52 \\
\hline $\mathrm{AUEC}_{\mathrm{REL}} \mathrm{AMPL}$ & $169(114-204)$ & $195(148-223)$ & $0.89(0.80-0.96)$ & 0.012 \\
\hline \multicolumn{5}{|c|}{ Multiple doses, extensive metabolisers $(n=8)$} \\
\hline AUEC $_{\text {MAX }}$ & $3435(2901-3653)$ & $3434(2940-3645)$ & $0.95(0.90-1.01)$ & 0.071 \\
\hline $\mathrm{AUEC}_{\mathrm{REL}} \mathrm{AMPL}$ & $175(112-210)$ & $193(152-223)$ & $0.88(0.88-0.96)$ & 0.009 \\
\hline
\end{tabular}

$830 \mathrm{nmol} / \mathrm{L} \mathrm{h}$ in the PM group [9]. These two mean values indicate a 1.6-fold higher AUC in the PM than in the EM, which is in good agreement with our data. In a recent study, the PK of escitalopram was determined in a group of 17 healthy subjects after multiple doses of escitalopram $10 \mathrm{mg} /$ day [18]. The results are fairly consistent with our results obtained in the group of EM subjects. The discrepancy in AUC and CL/F may have been caused by the fact that three subjects in the earlier study were CYP2C19 PM whose $\mathrm{CL} / \mathrm{F}$ ranged from 10 to $12 \mathrm{~L} / \mathrm{h}$, which is in good agreement with the $\mathrm{CL} / \mathrm{F}$ range $(8-16 \mathrm{~L} / \mathrm{h})$ found in our study. The exact times of blood sampling after the drug has been administered are crucial when estimating $\mathrm{C}_{\max }$ and $\mathrm{t}_{\max }$, and differences in these parameters are, therefore, not of great significance. In a study based on data from therapeutic drug monitoring (TDM) files of a Norwegian psychiatric population, a 5.7-fold increase of dose-adjusted serum concentrations of escitalopram was found in subjects homozygous for defective $C Y P 2 C 19$ alleles compared to subjects carrying two functional alleles [19]. This difference from our findings may be due to differences in sample size or populations. Results based on TDM material tend to overestimate the difference in drug exposure between phenotypes, as the material is assumed to be affected by selection bias: samples from patients that have therapeutic failure are probably more likely to be EM, whereas PM patients probably more often receive TDM due to adverse drug reactions. In our study, there were no differences in CYP2C19 metabolic capacity, measured as $\mathrm{MR}_{\text {omeprazole, }}$ between the randomly selected screened population $(n=$ $306)$ and the study population $(n=13)$, separated in phenotype groups. This indicates that our estimates of the impact of CYP2C19 on escitalopram PK are reliable and can be extrapolated to the general population.

The difference between $\mathrm{AUC}_{0-24}$ (multiple dose) and $\mathrm{AUC}_{0-\infty}$ (single dose) found in this study is most likely explained by the short blood sampling period after the single dose administration; consequently, more than $50 \%$ of the individually estimated $\mathrm{AUC}_{0-\infty}$ were extrapolated.

Most of the PK values of demethylescitalopram, except $t_{1 / 2}$, were identical in the EM and PM. However, given the relatively long $t_{1} / 2$, steady state of demethylescitalopram could not be expected, and the PK values reported here are to be taken with caution.

There was a discrepancy between the CYP2C19 genoand phenotype for one subject; the omeprazole MR was 6.44 and the subject was thereby classified as PM by phenotype. The genotype is limited to the selected alleles tested for, and the * 1 phenotype is consequently not irrefutable evidence for a functional allele but only that no non-functional allele was detected. Hence, this subject may be a carrier of a nonfunctional allele that we did not test for.

We found no effect of escitalopram on the pupil diameter. This was surprising, considering the mydriatic effects demonstrated in a study of citalopram [12] and studies of other SSRIs [12, 20, 21]. The mydriatic effect of SSRIs has previously been explained by an increased sympathetic outflow of noradrenaline [12, 21, 22], but this may not be the case. Several SSRIs, including escitalopram and citalopram, have actually been demonstrated to decrease the firing activity of the noradrenergic neurons $[23,24]$. There is a significant difference in the effect on 
noradrenergic neurotransmission between escitalopram and citalopram that may be of a mechanistic nature and not simply a difference in potency [23], and this difference could explain the discrepancy in pupillary response between $10 \mathrm{mg}$ escitalopram and $20 \mathrm{mg}$ citalopram [12]. However, in a subsequent study, we actually found that escitalopram $20 \mathrm{mg} /$ day at steady state significantly increased the pupil diameter in 15 subjects, all CYP2C19 and CYP2D6 EM, and that the lack of response in the present study may be a simple question of dose dependence (manuscript submitted). Further, the central effect of SSRIs may be an interplay with a local effect in the eye: in recent studies, several serotonin receptor subtypes have been identified in the human eye by mRNA techniques $[24,25]$. The exact functions of these receptors are still to be determined but as some of the receptors are found on the dilator muscle of the pupil [24], a local mydriatic effect of SSRIs can not be excluded.

In conclusion, the CYP2C19 polymorphism significantly affects the metabolism of escitalopram. However, our findings do not justify dose adjustment based on CYP2C19 phenotypes. The puzzling results from pupillometry can be due to an interplay between a central noradrenergic effect and a local serotonergic effect. At present, pupillometry cannot be recommended as a serotonergic biomarker.

Acknowledgments The authors thank Henrik Berg Rasmussen, Research Institute of Biological Psychiatry, St. Hans Psychiatric Hospital, Roskilde, Denmark for the CYP2C19 genotyping.

\section{References}

1. Bareggi SR, Mundo E, Dell'Osso B et al (2007) The use of escitalopram beyond major depression: pharmacological aspects, efficacy and tolerability in anxiety disorders. Expert Opin Drug Metab Toxicol 3:741-753

2. Hyttel J, Bogeso KP, Perregaard J et al (1992) The pharmacological effect of citalopram residues in the $(\mathrm{S})-(+)$-enantiomer. J Neural Transm Gen Sect 88:157-160

3. Sánchez C (2006) The pharmacology of citalopram enantiomers: the antagonism by R-citalopram on the effect of S-citalopram. Basic Clin Pharmacol Toxicol 99:91-95

4. Waugh J, Goa KL (2003) Escitalopram : a review of its use in the management of major depressive and anxiety disorders. CNS Drugs 17:343-362

5. Sindrup SH, Brosen K, Hansen MG et al (1993) Pharmacokinetics of citalopram in relation to the sparteine and the mephenytoin oxidation polymorphisms. Ther Drug Monit 15:11-17

6. Ingelman-Sundberg M, Sim SC, Gomez A et al (2007) Influence of cytochrome $\mathrm{P} 450$ polymorphisms on drug therapies: pharmacogenetic, pharmacoepigenetic and clinical aspects. Pharmacol Ther 116:496-526

7. Ibeanu GC, Blaisdell J, Ferguson RJ et al (1999) A novel transversion in the intron 5 donor splice junction of CYP2C19 and a sequence polymorphism in exon 3 contribute to the poor metabolizer phenotype for the anticonvulsant drug S-mephenytoin. J Pharmacol Exp Ther 290:635-640
8. The Human Cytochrome P450 (CYP) Allele Nomenclature Committee (2007) Home page of the Human Cytochrome P450 (CYP) Allele Nomenclature Committee. Available at: http://www. cypalleles.ki.se/. Accessed 25 Mar 2009

9. Herrlin K, Yasui-Furukori N, Tybring G et al (2003) Metabolism of citalopram enantiomers in CYP2C19/CYP2D6 phenotyped panels of healthy Swedes. Br J Clin Pharmacol 56:415-421

10. Rudberg I, Hendset M, Uthus LH et al (2006) Heterozygous mutation in CYP2C19 significantly increases the concentration/ dose ratio of racemic citalopram and escitalopram (S-citalopram). Ther Drug Monit 28:102-105

11. Fliegert F, Kurth B, Gohler K (2005) The effects of tramadol on static and dynamic pupillometry in healthy subjects-the relationship between pharmacodynamics, pharmacokinetics and CYP2D6 metaboliser status. Eur J Clin Pharmacol 61:257-266

12. Schmitt JA, Riedel WJ, Vuurman EF et al (2002) Modulation of the critical flicker fusion effects of serotonin reuptake inhibitors by concomitant pupillary changes. Psychopharmacology (Berl) 160:381-386

13. U.S. Food and Drug Administration (FDA) (2006) Drug development and drug interactions. FDA, Washington D.C. Available at: http://www.fda.gov/cder/drug/druginteractions/. Accessed 23 Mar 2009

14. Roh HK, Dahl ML, Tybring G et al (1996) CYP2C19 genotype and phenotype determined by omeprazole in a Korean population. Pharmacogenetics 6:547-551

15. Chang M, Dahl ML, Tybring G et al (1995) Use of omeprazole as a probe drug for CYP2C19 phenotype in Swedish Caucasians: comparison with S-mephenytoin hydroxylation phenotype and CYP2C19 genotype. Pharmacogenetics 5:358-363

16. Goldstein JA, Blaisdell J (1996) Genetic tests which identify the principal defects in CYP2C19 responsible for the polymorphism in mephenytoin metabolism. Methods Enzymol 272:210-218

17. Ferguson RJ, De Morais SM, Benhamou S et al (1998) A new genetic defect in human CYP2C19: mutation of the initiation codon is responsible for poor metabolism of S-mephenytoin. J Pharmacol Exp Ther 284:356-361

18. Sogaard B, Mengel H, Rao N et al (2005) The pharmacokinetics of escitalopram after oral and intravenous administration of single and multiple doses to healthy subjects. J Clin Pharmacol 45:14001406

19. Rudberg I, Mohebi B, Hermann M et al (2008) Impact of the ultrarapid CYP2C19*17 allele on serum concentration of escitalopram in psychiatric patients. Clin Pharmacol Ther 83:322-327

20. Saletu B, Grunberger J, Linzmayer L (1986) On central effects of serotonin reuptake inhibitors - quantitative EEG and psychometric studies with sertraline and zimelidine. J Neural Transm 67:241-266

21. Mcguirk J, Silverstone T (1990) The effect of the 5-HT reuptake inhibitor fluoxetine on food-intake and body-weight in healthy male-subjects. Int J Obes 14:361-372

22. Saletu B, Grunberger J, Linzmayer L (1986) On central effects of serotonin reuptake inhibitors - quantitative EEG and psychometric studies with sertraline and zimelidine. J Neural Transm 67:241-266

23. Blier P, El Mansari M (2007) The importance of serotonin and noradrenaline in anxiety. Int J Psychiat Clin 11:16-23

24. Chidlow G, Hiscott PS, Osborne NN (2004) Expression of serotonin receptor mRNAs in human ciliary body: a polymerase chain reaction study. Graefes Arch Clin Exp Ophthalmol 242:259-264

25. Sharif NA, Senchyna M (2006) Serotonin receptor subtype mRNA expression in human ocular tissues, determined by RTPCR. Mol Vis 12:1040-1047 